\title{
PENERAPAN METODE PENGEMBANGAN WATERFALL UNTUK APLIKASI PENJUALAN DAN PEMBELIAN PADA TOKO
}

\author{
Muhammad A'fwan', Forkas Tiroy Santos B², Irawan Setiadi ${ }^{3}$ \\ ${ }^{1,2,3}$ Universitas Indraprasta PGRI \\ Jalan Raya Tengah Nomor 80, Kelurahan Gedong, Pasar Rebo, Jakarta Timur \\ 1afwanmuh17@gmail.com, ${ }^{2}$ ftsbunindra@gmail.com, 3 irawan.setiadi91@gmail.com
}

\begin{abstract}
ABSTRAK
Komputer merupakan suatu alat yang sangat penting di kehidupan ini, terutama bagi perusahaan terutama dalm hal membuat dan mencari data-data yang dibutuhkan dengan waktu yang singkat dan akurat sehingga kita dapat memanfaatkan sisa waktu dengan kegiatan lainnya. Permasalahan pada Toko Bangunan RimbaJaya adalah masih menggunakan transaksi manual, yang mana masih sering terjadi kesalahan dalam penghitungan dan pendataan sehingga berdampak pada penghasilan yang kurang baik. Tujuan dari penelitian untuk Pengefektifitasan dalam melakukan transaksi penjualan dan pembelian pada Toko Bangunan RimbaJaya. Metode penelitian yang digunakan adalah metode kualitatif, sedangkan metode pengembangannya menggunakan metode waterfall. Hasil dari penelitian agar sistem informasi lebih efisien.
\end{abstract}

Kata Kunci: Sistem Informasi, Penjualan toko, Desktop

\section{ABSTRACT}

Computers are one of the most important tools for companies where we can create and find the data needed quickly and accurately so that we can take advantage of the remaining time with other activities. The problem with the RimbaJaya Building Shop is that it still uses manual transactions, which still often make mistakes in counting and data collection so that it has an impact on poor income. The purpose of this research is for effectiveness in conducting sales and purchasing transactions at the RimbaJaya Building Shop. The research method used is a qualitative method, while the development method uses the waterfall method. The results of the research so that the information system is more efficient

Key Word: System Informatic, Shop sale, Desktop

\section{PENDAHULUAN}

Kemajuan teknologi setiap zaman semakin berkembang, seseorang yang telah menjadi tenaga ahli profesional akan semakin dicari oleh banyak perusahaan. Tidak lepas dari kemajuan teknologi tersebut, oleh karena itu diperlukan adanya fasilitas penunjang yang efektif seperti komputer.

Komputer merupakan suatu alat yang sangat penting di kehidupan ini, terutama bagi perusahaan terutama dalm hal membuat dan mencari data-data yang dibutuhkan dengan waktu yang singkat dan akurat sehingga kita dapat memanfaatkan sisa waktu dengan kegiatan lainnya.

Permasalahan pada Toko Bangunan Rimba Jaya adalah masih menggunakan transaksi manual, yang mana masih sering terjadi kesalahan dalam penghitungan dan pendataan sehingga berdampak pada penghasilan yang kurang baik.
Kondisi ini menarik Penulis untuk melakukan penelitian dan merubah suatu sistem aplikasi yang ada agar memudahkan semua proses pengolahan data-data dan transaksi jual beli barang. Dalam pembuatan skripsi ini, penulis membuat judul "Penerapan Metode Pengembangan Waterfall untuk Aplikasi Penjualan dan Pembelian Pada Toko". Sistem aplikasi desktop berbasis open source ini diharapkan dapat membuat kemudahan dalam mendapatkan informasi yang diperlukan.

Rancang bangun ialah proses membangun sistem bertujuan membuat sistem terbarukan dan memperbaiki sistem yang ada secara keseluruhan atau beberapa bagian. (Sari, 2017)

Seperti kita ketahui bersama bahwa semakin banyak pakar mengartikan sistem. Definisi sistem dalam penelitian ini adalah pemahaman yang dijelaskan oleh Sutabri. Sutabri 
menjelaskan pemahaman sistem sebagai sekumpulan elemen yang kuat entitasnya satu sama lain, yang berfungsi untuk mencapai tujuan tertentu. Dengan kata lain, sistem diartikan sebagai kumpulan atau kelompok elemen, komponen, atau variabel yang terorganisasi, saling berhubungan, saling bergantung, dan terintegrasi. Pada hakikatnya, system ini adalah kumpulan entitas (perangkat keras, brainware, perangkat lunak) yang berinteraksi, bekerj bersama dan berkolaborasi untuk mencapai tujuan tertentu.(Herliana \& Rasyid, 2016)

Informasi dapat diartikan hasil pemrosesan data dalam bentuk yang lebih bermanfaat dan besar untuk penerima yang menggambarkan suatu kegiatan (event) nyata (fact) yang digunakan untuk proses pengambilan keputusan. (Priyanti, 2013).

Sistem informasi adalah suatu sistem dalam satu organisasi yang menyatukan kebutuhan pemrosesan transaksi sehari-hari, menguatkan operasi managerial serta kegiatan strategis suatu organisasi dan menyiapkan pihak luar tertentu dengan laporan yang diinginkan.(Solihin \& Fuja Nusa, 2017).

Pembelian merupakan proses dimana suatu perusahaan menginginkan barang atau jasa, baik digunakan maupun sebagai persediaan yang akan dijual (Himayati, 2008). Pembelian dapat didefinisikan sebagai pembayaran (purchasing) yang digunakan untuk mencatat dan menyimpan semua pembelian barang dagangan pada waktu tertentu. (Soemarso, 2009).(Fatkhudin, 2016)

Penjualan ialah upaya terpadu untuk menyusun rencana strategis yang diarahkan untuk memuaskan kebutuhan dan keinginan pembeli, agar mendapatkan penjualan yang menghasilkan keuntungan.(Noviandhiny et al., 2018)

Netbeans adalah IDE yang dipopulerkan dengan bahasa pemrograman java. Netbeans memiliki ruang lingkup pemrograman java yang terintegrasi dalam sebuah perangkat lunak yang meliputi penyediaan pengembangan pemrograman GUI, editor teks, compiler, dan interpreter. Netbeans adalah perangkat lunak open source yang dapat digunakan secara cumacuma untuk tujuan komersil dan nonkomersil yang dibantu oleh Sun Microsystem.(Utami \& Purnama, 2014)

DFD adalah alat desain sistem yang berorientasi pada beberapa aliran data dengan memiliki beberapa konsep dekomposisi yang dapat digunakan dalam menggambarkan atau menganalisis desain sistem untuk dikomunikasikan oleh para profesional sistem kepada mereka yang menggunakan dan yang membuat program.(Dhika et al., 2019)

Metode air terjun merupakan metode yang sering dipakai pada tahap perancangan. Metode air terjun (waterfall) sering juga disebut model sekuensial linier (squential linear) atau siklus klasik (Classic cycle). Metode air terjun ini memberikan pendekatan alur hidup perangkat lunak secara berurutan dan terurut dimulai dari tahap analisis, desain, pengkodean, pengujian dan tahap dukungan (support).(Susilo, 2018)

\section{METODE PENELITIAN}

Metode penelitian dalam penelitian ini adalah metode kualitatif bertujuan dapat memahami suatu obyek yang alamiah, atau natural sehingga penelitian ini disebut penulisan naturalistic, untuk mengembangkan konsep kepekaan terhadap masalah yang dihadapi, dan tidak dimanipulasi oleh penulis.

Metode pengembangan data yang digunakan adalah metode waterfall yang merupakan satu dari sekian jenis model pengembangan aplikasi yang termasuk dalam siklus hidup klasik yang menekankan pada urutan dan tahap sistem secara terstruktur dan sistematis. Untuk model pengembangan ini mirip dengan air terjun, dimana setiap tahapan dijalankan secara berurutan dari atas ke bawah.

Berikut alur pengembangan sistem dengan metode Waterfall: 


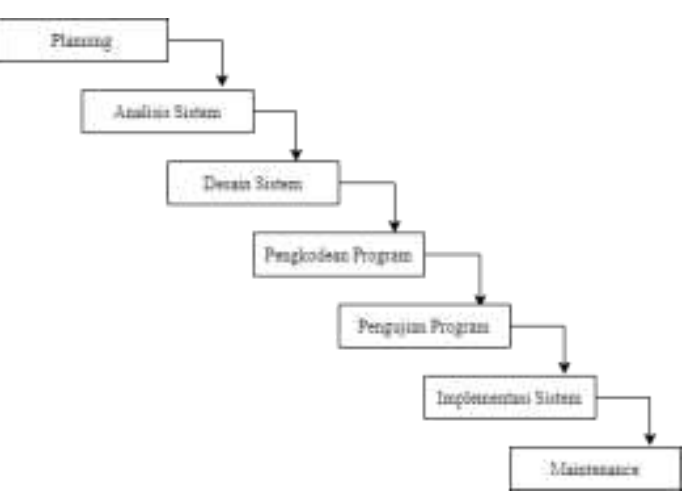

Gambar 1. Waterfall

\section{Planning (Perencanaan)}

Pada tahap ini dilakukan untuk melihat kebutuhan yang ada pada projek. Proses ini termasuk menghitung tenaga kerja dan sumber daya material yang dibutuhkan, menetapkan jadwal dengan tujuan dan sasaran, serta membentuk tim dan struktur kepemimpinan untuk projek.

2. Analis Sistem

Langkah kedua dari metode waterfall adalah menyiapkan dan menganalisis kebutuhan perangkat lunak yang akan diselesaikan. Kebutuhan tersebut dapat dilihat dari hasil wawancara, survei dan oservasi.

3. Desain Sistem

Pada tahap ini, akan dibuat gambaran sistem secara keseluruhan dan menentukan detail algoritma untuk alur software.

4. Pengkodean Program

Pada proses ini adalah implementasi kode pemrograman sesuai kebutuhan yang menggunakan berbagai tools dan bahasa pemrograman seperti Java.

5. Pengujian Sistem

Tahap kelima memasuki proses pengujian. Pada fase ini, modul yang dibuat pada fase sebelumnya akan digabungkan.

6. Implementasi

Pada tahap implementasi, kondisi dan tujuan kerangka sistem harus dipertimbangkan saat melakukan implementasi struktur dan alur kerja.

7. Maintenance

Tahap terakhir dari metode waterfall adalah pengoperasian dan perbaikan aplikasi.

\section{HASIL DAN PEMBAHASAN}

Berdasarkan masalah - masalah yang dihadapi dalam melakukan proses transaksi jual dan beli pada toko bangunan rimba jaya, oleh karena itu penulis menyajikan beberapa alternatif penyelesaian masalahnya, yaitu:

1. Bagaimana membuat sistem transaksi penjualan dan pembelian pada Toko Bangunan RimbaJaya dengan efektif dan efesien serta mempermudah dalam proses perhitungan harga secara komputerisasi.

2. Bagaimana membuat sistem pendataan pada Toko Bangunan Rimba Jaya yang mudah dan tidak terjadi kesalahan memasukan data agar data yang telah dibuat dapat tersimpan dengan baik dan terjamin keamananya.

3. Bagaimana mempermudah pegawai dalam membuat laporan pada Toko Bangunan Rimba Jaya agar tidak terjadi kesalahan dalam membuat laporan dan menyimpan setiap laporan dengan aman.

Berikut merupakan gambaran dari sistem yang diajukan pada Rancang Bangun Sistem Informasi Penjualan dan Pembelian Pada Toko Bangunan RimbaJaya secara menyeluruh dalam bentuk diagram konteks:

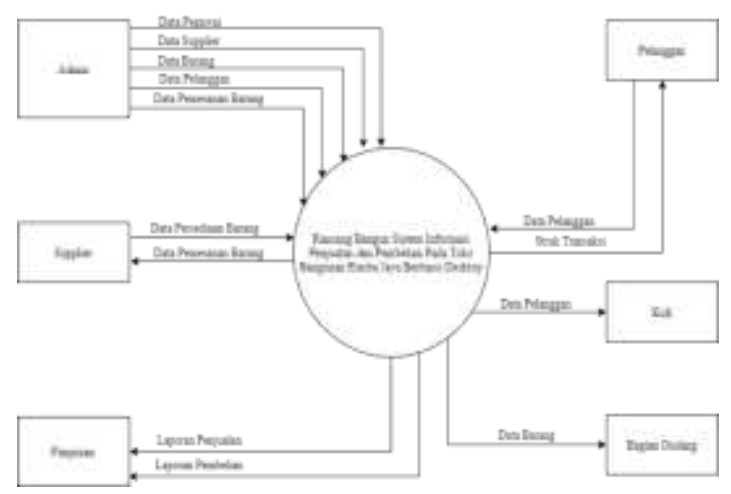

Gambar 2. Diagram Konteks yang Diusulkan

Entity Relatioship Diagram (ERD) adalah penggambaran tahap awal database yang dikembangkan sesuai dengan teori himpunan dalam bidang matematika untuk penggambaran database relational.(Calista, 2015) 


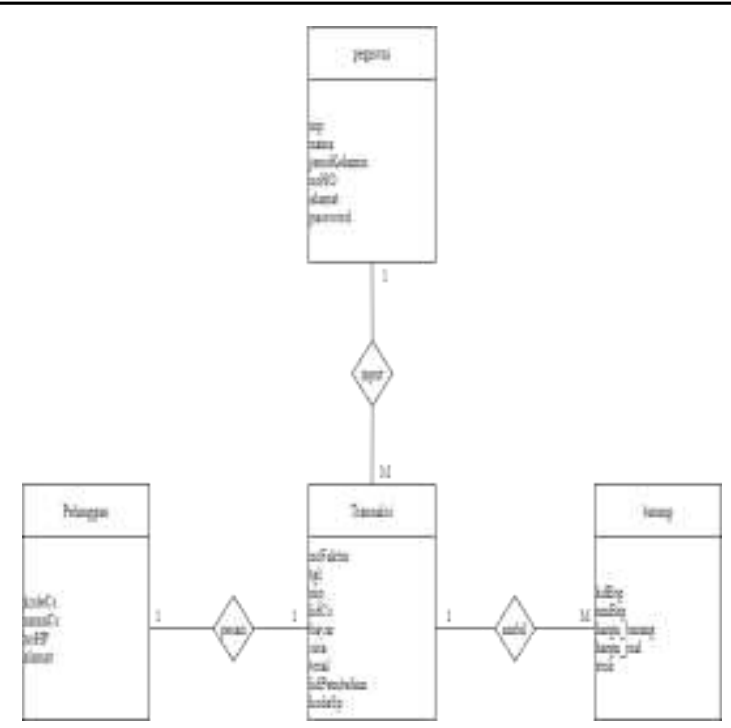

Gambar 3. Entity Relationship Diagram (ERD)

Berikut ini adalah tampilan dan hasil percobaan pada software program yang telah dibuat dari bahasa pemrograman Java.

Tampilan Layar Aplikasi Penjualan dan Pembelian Toko Bangunan Rimba Jaya Berikut ini merupakan tampilan layar pada aplikasi penjualan dan pembelian pada toko bangunan rimbajaya.

\section{Tampilan Login}

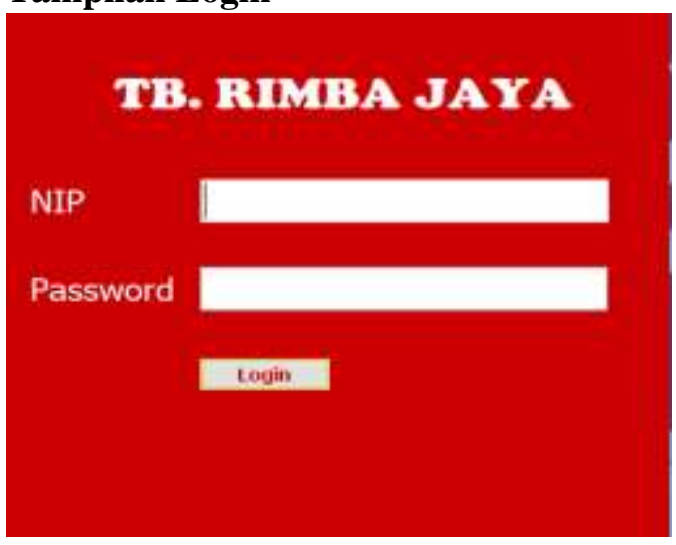

Gambar 4. Tampilan Login

Pada tampilan login admin akan memasukan NIP dan password yang sudah terdaftar agar bisa mengoperasikan aplikasi.
Tampilan Beranda

\section{SISTEM INFORMAST TMANSAKSI \\ TOKO BANGUNAN RMBa JAYA}

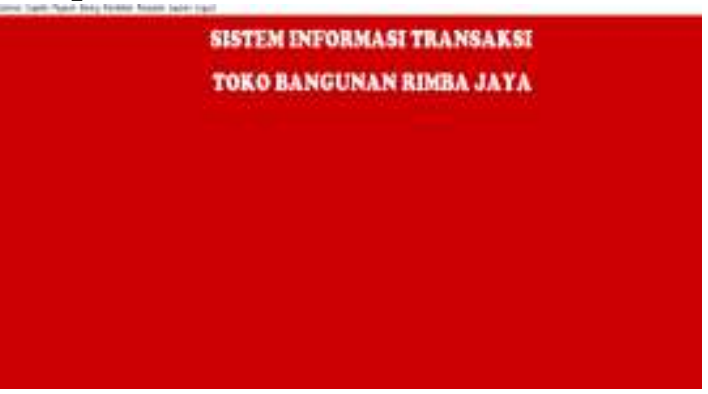

Gambar 5. Tampilan Beranda

Tampilan beranda atau menu adalah tampilan awal setelah login dan tempat form-form masukan data,transaksi, dan form keluaran data.

\section{Tampilan Data Pegawai}

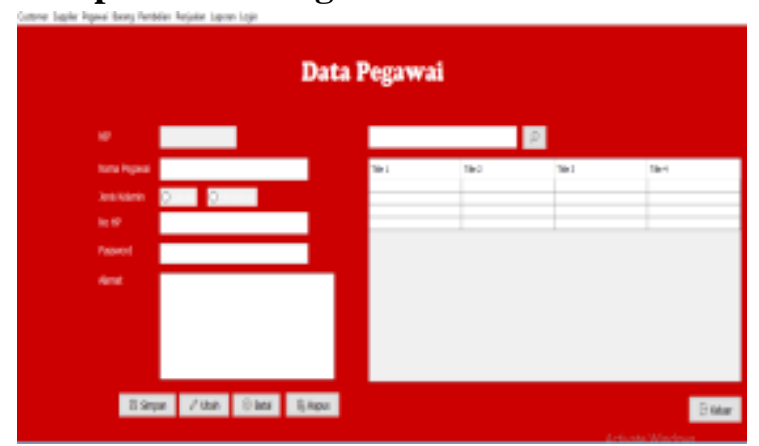

Gambar 6. Tampilan Data Pegawai

Tampilan isian data pegawai untuk menyimpan dan mendata setiap pegawai yang aktif bekerja di toko.

\section{Tampilan Data Barang}

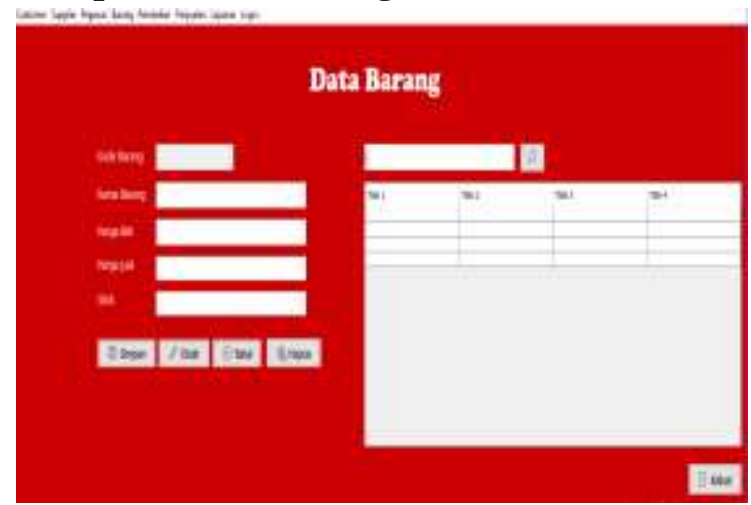

Gambar 7. Tampilan Data Barang

Tampilan isian data barang untuk menginput dan menyimpan data setiap barang yang tersedia didalam tempat barang maupun yang akan masuk ke dalam gudang. 


\section{Tampilan Data Supplier}

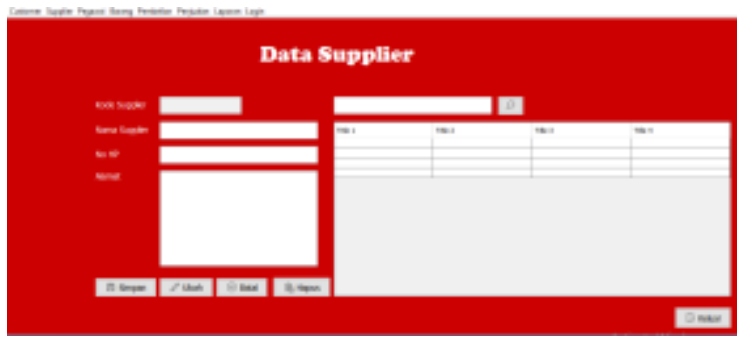

Gambar 8. Tampilan Data Supplier

Tampilan data supplier untuk mendata setiap supplier yang telah bekerjasama maupun yang baru bekerjasama dengan toko.

\section{Tampilan Data Pelanggan}

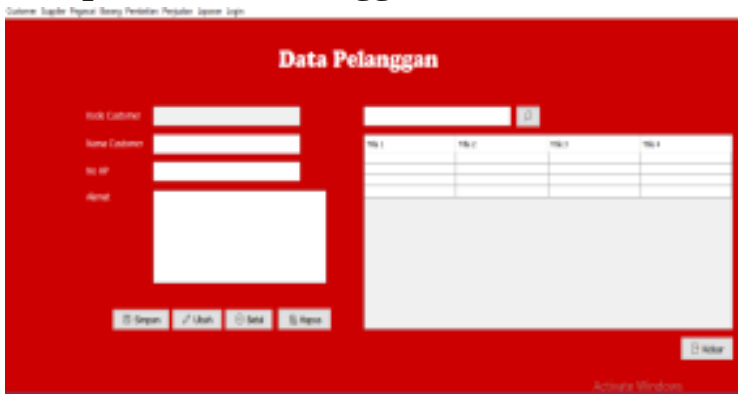

Gambar 9. Tampilan Data Pelanggan

Tampilan isian data pelanggan untuk mendata setiap pelanggan yang akan memesan atau membeli barang untuk dilanjutkan ke tahap transaksi.

\section{Tampilan Transaksi Penjualan}

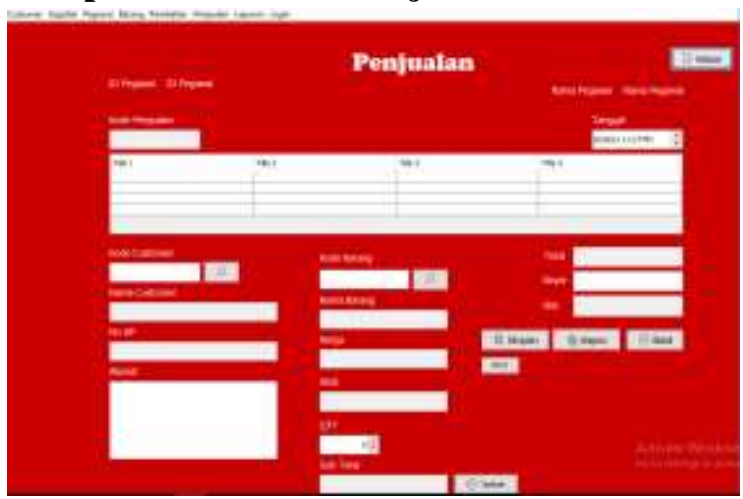

Gambar 10. Tampilan Transaksi Penjualan

Tampilan form transaksi penjualan adalah proses transaksi antara admin/petugas dengan pelanggan yang telah atau akan memesan barang.
Tampilan Transaksi Pembelian

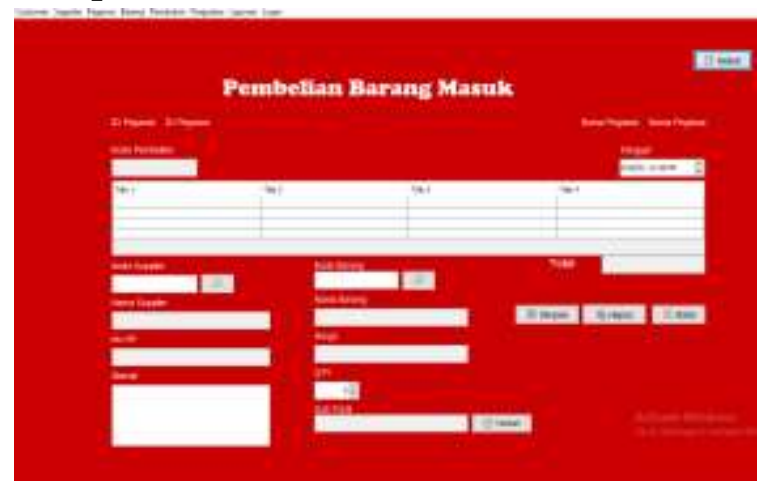

Gambar 11. Tampilan Transaksi Pembelian

Tampilan form transaksi pembelian merupakan aktivitas transaksi terhadap barang yang akan dipesan dari supplier, lalu akan tersimpan pada laporan data barang.

\section{Tampilan Laporan Data Pegawai}

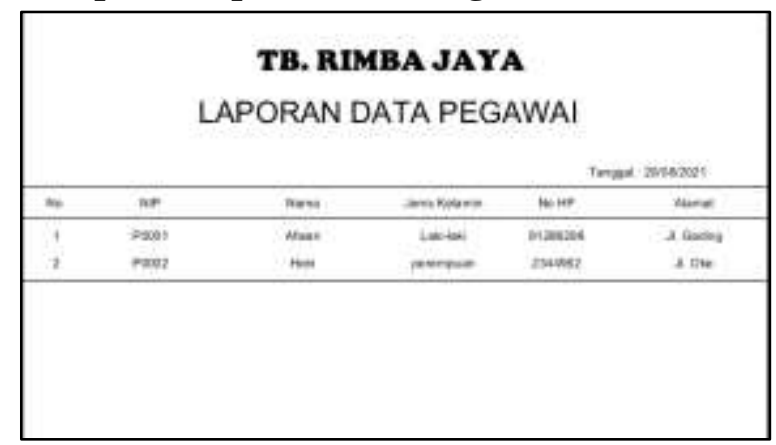

Gambar 12. Tampilan Laporan Data Pegawai

Tampilan form laporan data pegawai untuk laporan kepada pimpinan sebagai bukti pegawai yang bekerja.

\section{Tampilan Laporan Data Barang}

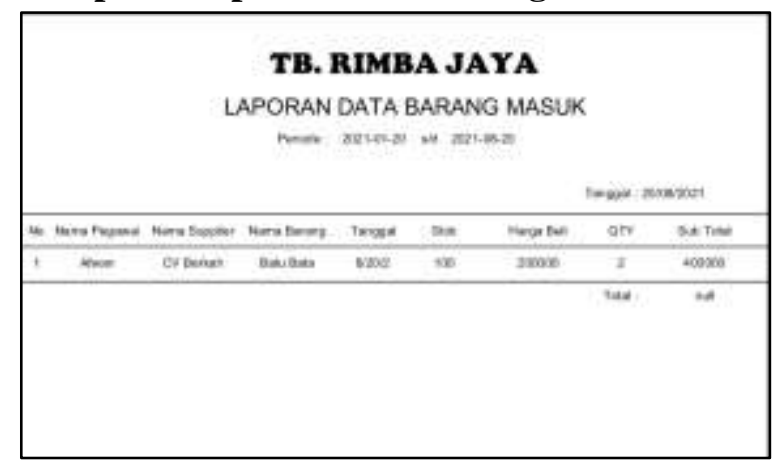

Gambar 13. Tampilan Laporan Data Barang

Pada tampilan laporan data barang ini, menyimpan data barang yang baru dibeli atau barang yang tersedia pada gudang. 


\section{Tampilan Laporan Data Supplier}

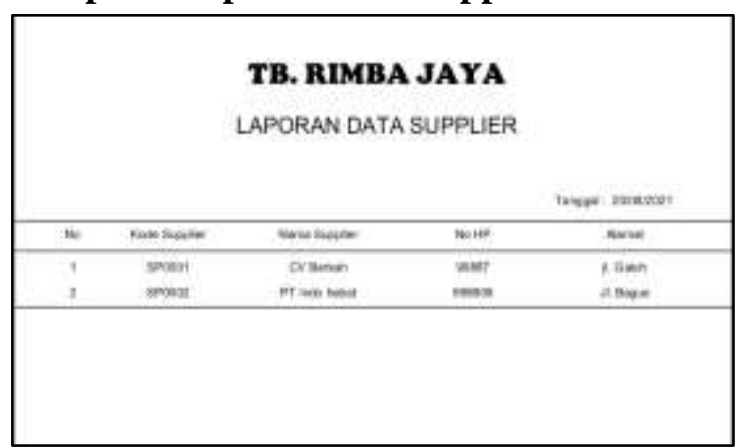

Gambar 14. Tampilan Laporan Data Supplier

Tampilan laporan data supplier adalah laporan untuk setiap bukti transaksi pembelian barang yang akan ditujukan kepada pimpinan.

\section{Tampilan Laporan Data Pelanggan}

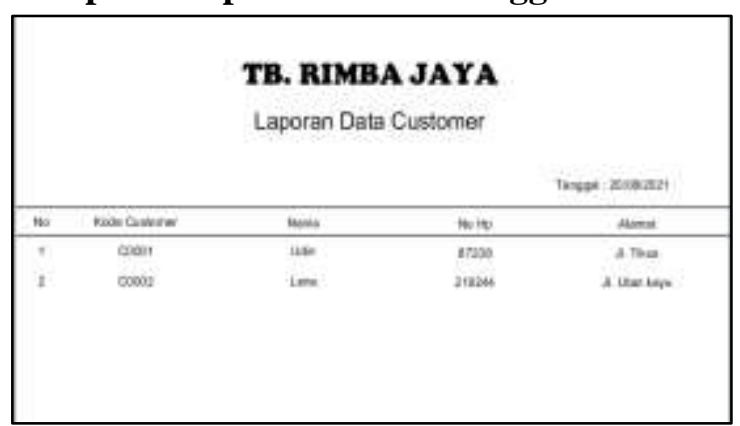

Gambar 15. Tampilan Laporan Data Pelanggan

Tampilan laporan data pelanggan adalah laporan pelanggan yang telah melakukan pembayaran dan akan diberikan kepada pimpinan sebagai bukti.

\section{Tampilan Laporan Data Penjualan}

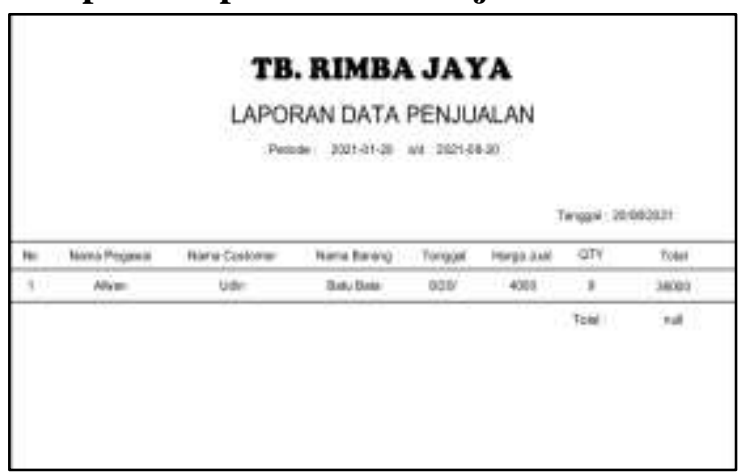

Gambar 16. Tampilan Laporan Data Penjualan

Tampilan laporan data penjualan adalah laporan setiap sebulan sekali terhadap penjualan barang yang telah terjual dan ditujukan untuk pimpinan sebagai bukti laporan.

\section{SIMPULAN DAN SARAN}

Berdasarkan hasil uraian hasil sistem, dapat disimpulkan bahwa dapat memudahkan operator dalam pengisian data pelanggan dan tidak perlu lagi melakukan pencatatan di buku, dapat mempercepat proses pendataan pelanggan,barang,pegawai dan lain sebagainya disebuah toko, tampilan yang sangat familiar sehingga sangat mudah dimengerti dan mudah digunakan oleh operator untuk melakukan pencatatan. Sistem yang dibuat dalam bentuk aplikasi dekstop yang dapat dijalankan langsung di komputer. Sistem pendataan menjadi lebih efisien dan sistem informasi pada toko bangunan rimba jaya dikembangkan dengan menggunakan database MySQL sebagai media penyimpanannya sehinggan aman dan dapat dengan mudah dikontrol.

Agar memperoleh hasil yang memuaskan dalam pengembangan aplikasi ini, disarankan pihak toko agar melakukan beberapa hal dalam menerapkannya, yaitu melakukan pelatihan kepada pegawai yang akan menggunakan aplikasi desktop ini. Hal ini bertujuan agar aplikasi ini dapat digunakan dengan baik. Mencari solusi untuk pencatatan persediaan, karena persediaan disini bersifat ambigu pada satuan (contoh: satuan pasir,batu dll.). Perlunya menambahkan fitur-fitur baru untuk kedepan sesuai dengan kebutuhan toko seperti sistem persediaan.

\section{DAFTAR PUSTAKA}

Calista, B. (2015). Aplikasi Pengolahan Data Pemesanan Barang Pada Cv Fitrana Palembang. Politeknik Negeri Sriwijaya.

Dhika, H., Isnain, N., \& Tofan, M. (2019). Manajemen Villa Menggunakan Java Netbeans Dan Mysql. IKRA-ITH INFORMATIKA : Jurnal Komputer Dan Informatika, 3(2), 104-110. https://journals.upiyai.ac.id/index.php/ikraithinformatika/article/view/324

Fatkhudin. (2016). Toko Elektronik Lubada Jaya Kajen Dengan. 6(1), 23-36.

Herliana, A., \& Rasyid, P. M. (2016). Sistem Informasi Monitoring Pengembangan Software Pada Tahap. Jurnal Informatika, $1,41-50$.

Noviandhiny, P., Nasution, H., \& Esyudha 
Pratama, E. (2018). Rancang Bangun Aplikasi Penjualan dan Pembelian Berbasis Web Pada Apotek Neofarma Sanggau. Jurnal Sistem Dan Teknologi Informasi (JUSTIN), 6(3), 129. https://doi.org/10.26418/justin.v6i3.25770 Priyanti, D. (2013). Sistem Informasi Data Penduduk Pada Desa Bogoharjo Kecamatan Ngadirojo Kabupaten Pacitan. IJNS - Indonesian Journal on Networking and Security, 2(4), 56. ijns.org

Sari, Y. P. (2017). Rancang Bangun Aplikasi Penjualan Dan Persediaan Di Kota Prabumulih. Jurnal Sistem Informasi Dan Komputerisasi Akuntansi (JSK), 1(1), 8188. http://jsk.ac.id/index.php/JSK/article/view $/ 11$

Solihin, H. H., \& Fuja Nusa, A. A. (2017). Rancang Bangun Sistem Informasi Penjualan, Pembelian Dan Persediaan Suku Cadang Pada Bengkel Tiga Putra Motor Garut. Infotronik: Jurnal Teknologi Informasi Dan Elektronika, 2(2), 107. https://doi.org/10.32897/infotronik.2017.2 .2 .37

Susilo, M. (2018). Rancang Bangun Website Toko Online Menggunakan Metode Waterfall. InfoTekJar (Jurnal Nasional Informatika Dan Teknologi Jaringan), 2(2), $\quad$ 98-105. https://doi.org/10.30743/infotekjar.v2i2.1 71

Utami, T., \& Purnama, B. E. (2014). Pembangunan Sistem Informasi Penjualan Obat Pada Apotek Punung. IJMS Indonsian Journal on Medical Science, 9330(1), 1-7. 